\title{
Medication Reconciliation Practices in Canadian Emergency Departments: A National Survey
}

\author{
Richard Wanbon, Catherine Lyder, Eric Villeneuve, Stephen Shalansky, Leslie Manuel, \\ and Melanie Harding
}

\begin{abstract}
Background: As of 2015, Accreditation Canada’s Qmentum program expects emergency departments (EDs) to initiate medication reconciliation for 2 groups of patients: (1) those with a decision to admit and (2) those without a decision to admit who meet the criteria of a risk-based, health care organization-defined selection process. Pharmacist-led best possible medication histories (BPMHs) obtained in the ED are considered more complete and accurate than BPMHs obtained by other ED providers, with pharmacy technicians obtaining BPMHs as effectively as do pharmacists. A current assessment of the role of pharmacy in BPMH processes in Canadian EDs is lacking.

Objectives: To identify and describe BPMH and medication reconciliation practices in Canadian EDs, including those performed by members of the ED pharmacy team.

Methods: All Canadian hospitals with an ED and at least 50 acute care beds were contacted to identify the presence of dedicated ED pharmacy services (defined as at least a 0.5 full-time equivalent position). Different electronic surveys were then distributed to ED pharmacy team members (where available) and ED managers (all hospitals).

Results: Survey responses were obtained from 60 (63\%) of 95 ED pharmacy teams and 128 (53\%) of 243 ED managers. Only 38 (30\%) of the $128 \mathrm{ED}$ managers believed that their current $\mathrm{BPMH}$ processes were adequate to obtain a BPMH for all admissions. Fifty-nine (98\%) of the $\mathrm{ED}$ pharmacy personnel reported obtaining BPMHs (most commonly 6-10 per day), with priority given to admitted patients. Only 14 (23\%) of the $60 \mathrm{ED}$ pharmacy teams reported that their EDs had adequate staffing to comply with Accreditation Canada's requirements for obtaining BPMHs. This result is supported by the 104 (81\%) out of $128 \mathrm{ED}$ managers who reported that additional ED staffing would be needed to comply with the requirements. Numerous ED managers identified the need to expand ED pharmacy services and improve information technology support.
\end{abstract}

Conclusions: BPMH processes in Canadian EDs were variable and inadequately supported. Survey responses suggested that additional staff and significant improvements in structured processes would be required to meet Accreditation Canada standards.

Keywords: emergency department, medication reconciliation, pharmacist, pharmacy, survey

\section{RÉSUMÉ}

Contexte : À compter de 2015, le programme Qmentum d'Agrément Canada s'attend à ce que les services des urgences réalisent un bilan comparatif des médicaments pour deux groupes de patients : (1) ceux que l'on décide d'admettre et (2) ceux non admis qui présentent un risque d'événements indésirables liés aux médicaments selon des critères élaborés par l'organisme. Les meilleurs schémas thérapeutiques possibles (MSTP) obtenus au service des urgences grâce aux pharmaciens sont considérés comme étant plus complets et précis que ceux dressés par d'autres fournisseurs du service des urgences. De plus, ceux obtenus par les techniciens en pharmacie sont d'une qualité égale à ceux dressés par les pharmaciens. Enfin, il n'y a pas d'évaluation actuelle du rôle joué par le personnel de la pharmacie au sein des processus d'obtention des MSTP dans les services des urgences du Canada.

Objectifs : Recenser les pratiques de réalisation des MSTP et des bilans comparatifs des médicaments au sein des services des urgences canadiens, notamment celles des membres des équipes de pharmacie affectés aux services des urgences, et les décrire.

Méthodes : On a communiqué avec l'ensemble des hôpitaux canadiens disposant d'un service des urgences et d'au moins 50 lits de soins de courte durée afin de savoir s'ils profitaient de services de pharmacie consacrés au service des urgences (ce qui était défini comme au moins 0,5 d'un poste équivalent temps plein). Différents sondages électroniques ont ensuite été envoyés : un aux membres du personnel de pharmacie affectés aux services des urgences (le cas échéant); et un aux gestionnaires des services des urgences (de tous les hôpitaux).

Résultats : Au total, 60 (63\%) des 95 équipes de pharmacie affectées aux services des urgences ont répondu au sondage, et 128 (53\%) des 243 gestionnaires des services des urgences ont fait de même. Seulement $38(30 \%)$ gestionnaires des services des urgences croyaient que leurs processus actuels convenaient à l'obtention des MSTP pour tous les patients admis. Cinquante-neuf (98\%) équipes de pharmacie affectées aux services des urgences ont déclaré dresser des MSTP (normalement de 6 à 10 par jour), la priorité étant accordée aux patients admis. Seules 14 (23\%) des 60 équipes de pharmacie affectées aux services des urgences jugeaient que leur service des urgences était doté d'un personnel suffisant pour satisfaire aux exigences d'Agrément Canada en ce qui a trait à l'obtention des MSTP. Ce résultat était corroboré par le fait que $104(81 \%)$ des 128 gestionnaires des services des urgences ont souligné le besoin de personnel supplémentaire au service des urgences afin de pouvoir respecter les exigences. Un grand nombre de gestionnaires des services des urgences ont reconnu la nécessité d'accroître la prestation des services de pharmacie aux services des urgences ainsi que le besoin d'améliorer le 


\section{Can J Hosp Pharm. 2015;68(3):202-9}

soutien par les technologies de l'information.

Conclusions : Les processus d'obtention des MSTP dans les services des urgences canadiens variaient et n'avaient pas un soutien adéquat. Les réponses aux sondages semblent indiquer que du personnel supplémentaire de même que d'importantes améliorations des processus structurés seraient nécessaires pour respecter les normes d'Agrément Canada.

Mots clés : service des urgences, bilan comparatif des médicaments, pharmacien, pharmacie, sondage

\section{INTRODUCTION}

$\mathrm{T}$ The need to improve medication reconciliation practices, which include obtaining best possible medication histories (BPMHs), is well recognized. Errors in collecting medication histories at the time of admission to hospital are common, ${ }^{1-5}$ and many of these errors lead to clinically significant harm. ${ }^{2}$ The Institute for Safe Medication Practices Canada has defined a $\mathrm{BPMH}$ as "a history created using 1) a systematic process of interviewing the patient/family; and 2) a review of at least one other reliable source of information to obtain and verify all of a patient's medication use (prescribed and non-prescribed)" ${ }^{6}$ Although obtaining BPMHs for admitted patients remains a challenge for hospitals, it is considered a cost-effective process. ${ }^{7}$ Improving BPMH practices is also associated with a reduction in potential adverse drug events. ${ }^{8,9}$ Medication-related adverse events account for 12\%-28\% of emergency department (ED) visits ${ }^{10}$ and are associated with longer stays in hospital and greater health care system costs. ${ }^{11-16}$

Accreditation Canada, Safer Healthcare Now! and the Canadian Society of Hospital Pharmacists' CSHP 2015 initiative have all identified medication reconciliation as a priority for Canadian hospitals. ${ }^{17-19}$ A Required Organizational Practice (ROP) of Accreditation Canada outlines expectations for the reconciliation of medications for $\mathrm{ED}$ patients with a decision to admit. Although the process should be initiated in the ED, it may be completed in the receiving inpatient unit. ${ }^{17}$ For on-site accreditation surveys starting in 2015, the ROP will be expanded to include initiation of medication reconciliation for a target group of ED patients who are not to be admitted to hospital (according to their risk as defined by the ED). ${ }^{20}$ CSHP 2015 objective 1.1 states that by $2015,100 \%$ of hospital pharmacists will ensure that medication reconciliation occurs on admission ${ }^{19}$; however, there is no mention that BPMHs should be obtained in the ED.

Obtaining complete and accurate BPMHs in the ED has been a considerable challenge. ${ }^{21-23}$ In the United States, the Joint Commission has recognized the numerous barriers to completing medication reconciliation in the ED and now requires only that medication reconciliation be completed by the receiving ward for the admitted patient, with completion of medication reconciliation in the ED only when deemed clinically necessary. ${ }^{24}$ Regardless, obtaining BPMHs in the ED may provide an opportunity for early identification of medication-related events. Some of the described challenges may be overcome with adequate staffing and standardization of BPMH processes.

Pharmacist-led BPMHs obtained in the ED are considered more complete and accurate than those obtained by other ED providers ${ }^{25-30}$ and are associated with a reduction in medication errors. ${ }^{31,32}$ In one Canadian study, over one-third of medicationrelated ED presentations identified by pharmacists were missed by ED physicians. ${ }^{10}$ Existing evidence supports the provision of medication reconciliation services by clinical pharmacy staff, but evidence-based recommendations and screening tools are needed to prioritize this service for patients who are at greater risk for adverse medication events. ${ }^{33,34}$ Pharmacists are also best suited to provide leadership for organizations that are developing medication reconciliation practices. ${ }^{35-37}$

The role of the pharmacy technician has expanded to encompass a variety of clinical activities, which include obtaining BPMHs. ${ }^{38,39}$ Pharmacy technicians obtain BPMHs just as effectively as pharmacists, ${ }^{40-42}$ and national groups now recommend hiring pharmacy technicians to support medication reconciliation processes in hospitals. ${ }^{35,43,44}$

Given the challenges of obtaining BPMHs and the recommendations that pharmacy staff be involved in medication reconciliation activities, an evaluation of current pharmacy-led $\mathrm{BPMH}$ and medication reconciliation services in Canadian EDs is of interest. The objectives of this study were to quantify and describe clinical pharmacy services that provide BPMH and medication reconciliation services in Canadian EDs and to describe ED managers' assessments of current BPMH and medication reconciliation processes in Canadian EDs.

\section{METHODS}

Canadian hospitals with at least 50 acute care beds and an ED were identified using provincial and territorial ministry of health reports. Internet searches and personal communications with specific hospitals and health care centres were used to identify hospitals in regions where such reports were not available (i.e., Manitoba, Yukon, Northwest Territories, and Nunavut). A minimum of 50 acute care beds was selected on the basis of feasibility, consistency with the Hospital Pharmacy in Canada $2011 / 2012$ Report, ${ }^{45}$ and a previous survey that did not identify any ED pharmacy services in 89 US hospitals with fewer than 50 acute care beds. ${ }^{46}$ There were no exclusion criteria. 
Hospitals that met the inclusion criteria were reached by telephone to obtain contact information for potential respondents. Charge nurses in the ED were asked whether the ED had a pharmacist or a pharmacy technician position of at least 0.5 full-time equivalent (FTE). The response to this question was verified by telephone with a pharmacist working in the pharmacy dispensary and/or the pharmacy manager at each hospital. In hospitals with more than $1 \mathrm{ED}$ pharmacist, contact information was requested for the most senior ED pharmacist at that site or the ED pharmacist who provided the most hours of service to the ED.

Both English and French versions of two different electronic surveys were developed by 7 Canadian pharmacists ( 5 of whom were ED pharmacists) using FluidSurveys version 4.0 (2011) software (FluidSurveys, Ottawa, Ontario):

- The survey for ED managers was forwarded to ED managers at all hospitals. This survey took about $3 \mathrm{~min}$ to complete, with survey questions assessing current BPMH and medication reconciliation practices in the ED. Only one response to this survey was collected from each hospital.

- The survey for ED pharmacy staff was forwarded to ED pharmacists (or ED pharmacy technicians at hospitals with no ED pharmacist) working at least 0.5 FTE in the ED. This survey took about 5-15 min to complete (based on the nature of the responses), with survey questions describing BPMH and medication reconciliation practices performed by ED pharmacy team members and the availability of this service (hours and days per week). Only one response to this survey was collected from each hospital.

The surveys were tested for face validity, but no validated survey process on this topic was available for the research group to utilize. Approval for the study was obtained from the Health Research Ethics Board of Island Health. One survey invitation and 2 reminders, all containing consent information, were sent by e-mail to each potential respondent. Consent was implied by responding to the survey. Responses to any questions in the survey were voluntary, and no compensation or other incentive was offered. Survey responses were collected between July and September 2013. Descriptive statistics were used to analyze the data. Data about other aspects of clinical pharmacy services in Canadian EDs collected in these 2 surveys are reported elsewhere in this issue. ${ }^{47}$

\section{RESULTS}

This study identified 243 hospitals in Canada with at least 50 acute care beds and an ED. After the preliminary telephone survey, electronic surveys were distributed to 243 ED managers and $95 \mathrm{ED}$ pharmacy staff, with variable response rates (Figure 1). For additional detail about the derivation of the study groups, see Figure 1 in the companion article. ${ }^{47}$

\section{Survey of ED Managers}

Just over half of the 128 responses from ED managers came from Ontario and Quebec hospitals, with small numbers of respondents from most other Canadian jurisdictions (Table 1). According to these survey responses, nurses, physicians, and paramedics conducted BPMH work at 108 (84\%), 77 (60\%), and 25 (20\%) of the hospitals, respectively, and 88 (69\%) of the hospitals had a standardized BPMH process. The ED manager at one hospital reported that patients completed their own

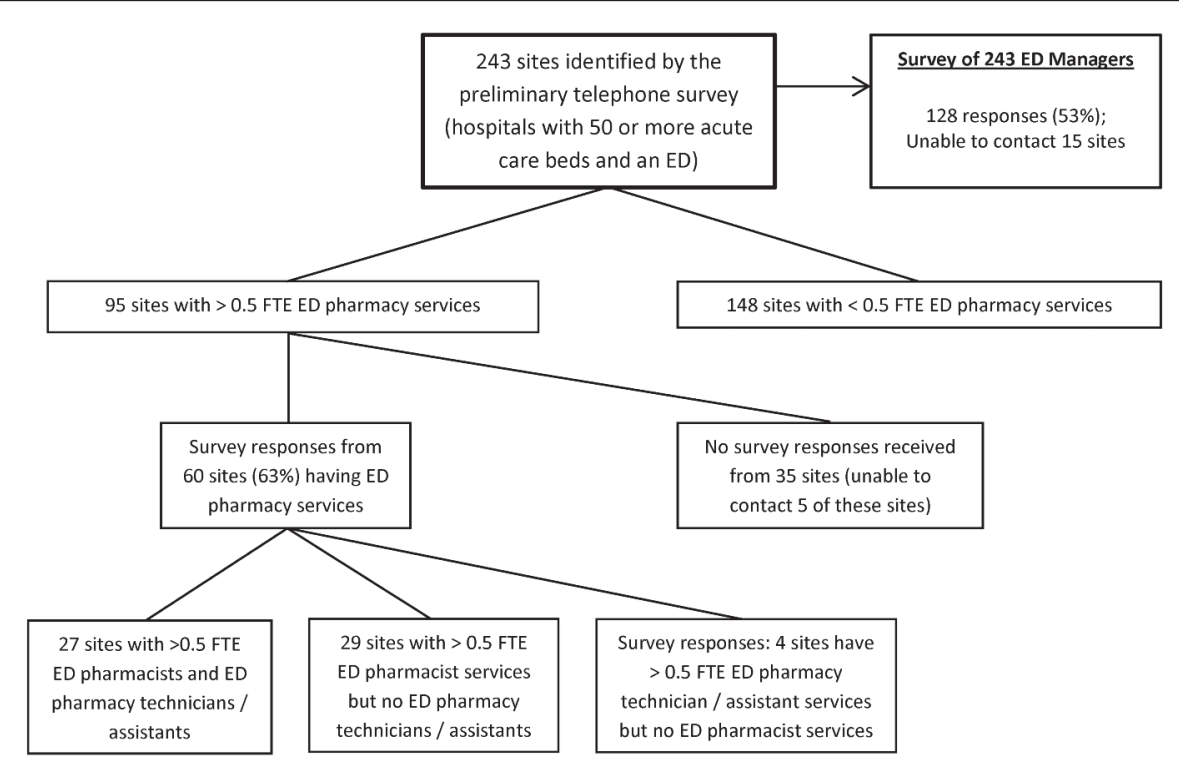

Figure 1. The distribution and response rates for a telephone survey and 2 electronic surveys targeting emergency department (ED) pharmacy teams and ED managers. FTE $=$ full-time equivalent. 
This single copy is for your personal, non-commercial use only.

For permission to reprint multiple copies or to order presentation-ready copies for distribution, contact CJHP at cjhpedit@cshp.ca

Table 1. Distribution of Responses to Survey of Emergency Department Managers

\begin{tabular}{lrr} 
Variable & $\begin{array}{r}\text { No. (\%) of Responses } \\
(\boldsymbol{n}=\mathbf{1 2 8})\end{array}$ \\
\hline Respondent's preferred language & 96 & $(75)$ \\
English & 32 & $(25)$ \\
French & & \\
Province or territory & 0 & $(0)$ \\
Yukon & 0 & $(0)$ \\
Northwest Territories & 1 & $(1)$ \\
Nunavut & 13 & $(10)$ \\
British Columbia & 10 & $(8)$ \\
Alberta & 8 & $(6)$ \\
Saskatchewan & 6 & $(5)$ \\
Manitoba & 37 & $(29)$ \\
Ontario & 35 & $(27)$ \\
Quebec & 2 & $(2)$ \\
Newfoundland and Labrador & 7 & $(5)$ \\
Nova Scotia & 4 & $(3)$ \\
New Brunswick & 1 & $(1)$ \\
Prince Edward Island & 4 & $(3)$ \\
Not identified & &
\end{tabular}

BPMHs. One hundred and four $(81 \%)$ of the ED managers expressed the need for additional staffing resources to support $\mathrm{BPMH}$ processes in the ED. Only 39 (30\%) of the ED managers believed that the current BPMH system available at their institutions was adequate for all admissions.

According to the ED managers, the following factors were used to prioritize BPMH work: admitted patients (102 [80\%]), severity of illness based on Canadian Triage and Acuity Scale assessments (19 [15\%]), age (11 [9\%]), and specific diagnoses (11 [9\%]). ED managers at $44(34 \%)$ of the hospitals also reported using a triage tool to identify patients who required a BPMH. Nineteen (15\%) of the ED managers reported that no $\mathrm{BPMH}$ prioritization process was in place.

Fifty-five of the ED managers shared comments about current or future BPMH processes in their departments. Thirtythree $(60 \%)$ of these comments supported the expansion of pharmacy services in the ED to obtain BPMHs. Improvements in information technology to support BPMH processes were also recommended.

\section{Survey of ED Pharmacy Team}

Of the 243 Canadian hospitals screened, up to 95 (39\%) had ED pharmacy services ( 90 with ED pharmacists and 5 with ED pharmacy technicians without pharmacists). However, because of incomplete survey responses, the absolute number of ED pharmacy services in Canada could not be confirmed in this study. The term "ED pharmacy services" is used here to refer to any ED with 0.5 FTE pharmacist and/or pharmacy technician dedicated to the ED. The survey of ED pharmacy staff collected information about the provision of pharmacy services in EDs
Table 2. Distribution of Responses to Survey of Emergency Department Pharmacists and Pharmacy Technicians

\begin{tabular}{|c|c|c|}
\hline Variable & $\begin{array}{r}\text { No. }(\%) \text { of } \\
\text { (n }\end{array}$ & $\begin{array}{l}\text { Responses* } \\
\text { 60) }\end{array}$ \\
\hline Respondent's preferred language & & \\
\hline English & 40 & $(67)$ \\
\hline French & 20 & (33) \\
\hline Province or territory & & \\
\hline Yukon & 0 & $(0)$ \\
\hline Northwest Territories & 0 & (0) \\
\hline Nunavut & 0 & (0) \\
\hline British Columbia & 5 & (8) \\
\hline Alberta & 4 & $(7)$ \\
\hline Saskatchewan & 1 & $(2)$ \\
\hline Manitoba & 7 & $(12)$ \\
\hline Ontario & 16 & $(27)$ \\
\hline Quebec & 18 & (30) \\
\hline Newfoundland and Labrador & 0 & $(0)$ \\
\hline Nova Scotia & 2 & (3) \\
\hline New Brunswick & 4 & (7) \\
\hline Prince Edward Island & 0 & (0) \\
\hline Not identified & 3 & (5) \\
\hline No. of ED visits/day & & \\
\hline $0-49$ & 10 & $(17)$ \\
\hline 50-99 & 12 & (20) \\
\hline $100-149$ & 11 & (18) \\
\hline 150-199 & 20 & (33) \\
\hline$\geq 200$ & 5 & (8) \\
\hline Not identified & 2 & (3) \\
\hline No. of ED admissions/day & & \\
\hline $0-9$ & 7 & $(12)$ \\
\hline 10-19 & 23 & (38) \\
\hline $20-29$ & 17 & (28) \\
\hline$\geq 30$ & 11 & (18) \\
\hline Not identified & 2 & (3) \\
\hline
\end{tabular}

*Percentages for some variables do not sum to exactly $100 \%$ because of rounding.

(including $\mathrm{BPMH}$ processes) from 56 pharmacists and 4 pharmacy technicians, representing a total of $60(63 \%)$ of the 95 hospitals with identified ED clinical pharmacy services. Geographic distribution and hospital-specific descriptors for these 60 respondents are presented in Table 2. As mentioned above, a more detailed description of clinical pharmacy services in Canadian EDs appears elsewhere in this issue. ${ }^{47}$ Of the $55 \mathrm{ED}$ pharmacist services that provided information about when the service was established, 44 (80\%) had been established within the 10 years preceding the survey. Seven hospitals had 2 or more ED pharmacists, and 11 hospitals had 2 or more ED pharmacy technicians. Most of these hospitals reported the provision of evening and weekend coverage.

ED pharmacy technician services were offered in at least 31 Canadian hospitals, mostly in eastern Canada: Quebec (16), Ontario (7), New Brunswick (4), Nova Scotia (1), Alberta (1), and Saskatchewan (1); location was not reported for one site. Of 
This single copy is for your personal, non-commercial use only.

For permission to reprint multiple copies or to order presentation-ready copies for distribution, contact CJHP at cjhpedit@cshp.ca

Table 3. Quantification of BPMH Activities by ED Pharmacy Services

\begin{tabular}{|c|c|c|c|c|c|c|c|}
\hline \multirow[b]{2}{*}{$\begin{array}{l}\text { Admissions/day from ED } \\
\text { (No. of Respondents) }\end{array}$} & \multicolumn{6}{|c|}{ No. of BPMHs/day; No. of Respondents } & \multirow[b]{2}{*}{$\begin{array}{c}\text { No } \\
\text { Response }\end{array}$} \\
\hline & 0 & $1-5$ & $6-10$ & $11-15$ & $16-20$ & $>20$ & \\
\hline $0-9(n=7)$ & 0 & 1 & 5 & 1 & 0 & 0 & 0 \\
\hline $10-19(n=23)$ & 2 & 3 & 7 & 5 & 4 & 2 & 0 \\
\hline $20-29(n=17)$ & 1 & 7 & 3 & 4 & 2 & 0 & 0 \\
\hline$>29(n=11)$ & 4 & 2 & 2 & 0 & 1 & 1 & 1 \\
\hline Unknown $(n=2)$ & 0 & 0 & 1 & 0 & 0 & 0 & 1 \\
\hline Total $(n=60)$ & 7 & 13 & 18 & 10 & 7 & 3 & 2 \\
\hline
\end{tabular}

$\mathrm{BPMH}=$ best possible medication history, ED = emergency department.

these, 24 (77\%) provided morning and afternoon service, and $10(32 \%)$ provided service 6 or 7 days per week. ED pharmacy technicians obtained BPMHs in 26 (84\%) of these 31 hospitals.

Fifty-nine (98\%) of the 60 ED pharmacy services reported active involvement in collecting BPMHs, with a wide range in the daily number of BPMHs obtained (Table 3). Of the 10 (17\%) ED pharmacy teams that reported obtaining more than 15 BPMHs each day, 7 represented hospitals with 2 or more pharmacy FTEs dedicated to the ED. Respondents from only 2 of these hospitals suggested that they had adequate staffing for BPMH work for all admitted patients in the ED. Overall, 46 (77\%) of ED pharmacy teams stated that they had inadequate ED staffing for obtaining BPMHs for all admitted patients. According to the ED pharmacy respondents, only $11(18 \%)$ of the hospitals had nonpharmacy staff completing BPMH work, and only $23(38 \%)$ of EDs had a standard BPMH process for all staff to follow.

The factors most commonly used to prioritize the collection of BPMHs were admitted patients (47 [78\%]), pharmacy consult requests $(35$ [58\%]), and specific diagnoses (11 [18\%]).

Use of a provincial database that tracks dispensed prescriptions was reported by 32 (53\%) of ED pharmacy respondents, with such databases also being used by nonpharmacy ED staff in all but one of the hospitals. Respondents from most hospitals reported that BPMHs were collected both before and after medication orders were written, but $6(10 \%)$ of the hospitals collected BPMHs exclusively before medication orders were written. Thirty-three (55\%) of the hospitals used a BPMH form that also functioned as an order form.

\section{DISCUSSION}

There is no agreement in the literature on what constitutes an acceptable survey response rate, but the response rates for the 3 surveys in this study fell within the range of various minimally acceptable response rates that have been reported previously ( $50 \%$ to $75 \%) .{ }^{48}$ Conducting this study during the summer months and not providing compensation or incentives may have adversely affected the response rates.

Numerous factors make the ED a difficult environment in which to obtain medication histories: large patient volumes, high patient - health care provider ratios, a large number of urgent or critical distractions, and shorter durations of stay relative to other wards. Many patients presenting to the ED are acutely ill and may be poorly prepared to provide detailed information about their existing medication therapy. Furthermore, their community pharmacies, family physicians, and family members may be unavailable to provide valuable information at the time of presentation. Given that obtaining BPMHs is time-consuming and requires a structured process and appropriate resources, it is not surprising that several studies have reported that trying to obtain BPMHs in ED triage areas leads to inaccurate and incomplete medication lists. ${ }^{21-23}$

The results of the current survey suggest that most Canadian EDs prioritize admitted patients for BPMH assessment, a practice that is consistent with the relevant Accreditation Canada ROP. ${ }^{17}$ However, evidence-based criteria to support this practice are lacking. Further research is needed to identify the most effective prioritization strategies for BPMH activities in the ED.

Obtaining a BPMH at the time of admission is both challenging and time-consuming, given that it must be obtained from multiple sources of information..$^{5}$ Information in a BPMH is typically more accurate when a regional database identifying dispensed prescription medications is available ${ }^{49}$; however, studies have also shown a considerable level of inaccuracy when medication lists are based solely on these databases. ${ }^{50-52}$ British Columbia, Saskatchewan, Manitoba, and Prince Edward Island may have the most complete and up-to-date prescription databases available, but the remaining provinces do not yet capture complete information about dispensed prescriptions in a timely manner from all community pharmacies.

At 33 (55\%) of the EDs represented by pharmacy team respondents, the forms used to collect the BPMH also served as order forms. Although such forms can provide a clearer comparison between home and hospital medications, integrating them into the medication order process can be challenging because the collection of BPMH data often occurs both before and after the medication orders are written. Electronic health records that incorporate an interface with central prescription databases may reduce these complications.

The survey did not request information about quality indicators to assess processes or outcomes. The importance of assessing this aspect of care may be highlighted by the differences 
in responses between ED pharmacy team members and ED managers. For example, a greater proportion of ED managers reported having a standard BPMH process and involving nonpharmacy staff in collecting the BPMH. Such differences may be due to different perspectives on the processes required to obtain a full BPMH and may warrant further research.

Accreditation Canada reported a 64\% compliance rate for initiating medication reconciliation in the ED among the 288 organizations that underwent an on-site accreditation survey in $2011.5^{33}$ It is curious that $70 \%$ of the $128 \mathrm{ED}$ managers in this study reported that their respective EDs were not able to effectively complete all admission BPMHs. Furthermore, about $80 \%$ of ED pharmacy team members and ED managers expressed the need for additional staffing resources to support $\mathrm{BPMH}$ processes in the ED for admitted patients. Starting in 2015, Accreditation Canada will require that EDs also initiate medication reconciliation for a risk-based, institution-defined selection of patients who will not be admitted to hospital. This new requirement stands to further challenge EDs. BPMH processes in Canadian EDs would ideally be supported by adequate levels of ED-based pharmacy staff. Close examination of processes is also required to identify potential improvements in efficiencies and outcomes.

This study showed a greater presence of ED pharmacy services in Canada than what has been reported in previous US studies, ${ }^{46,54,55}$ but a lower percentage than documented in the Hospital Pharmacy in Canada 2011/2012 Report. ${ }^{45}$ The current study's stringent definition of dedicated ED pharmacy services may explain the latter difference. Similar to previously published data, ${ }^{45,46} \mathrm{ED}$ pharmacist services in Canada were more common in larger hospitals. Fortuitously, this survey identified one hospital with a particularly robust model for ED pharmacy staffing, which could be used as a benchmark for other hospitals. ED pharmacy services at the South Health Campus in Calgary, Alberta, are described in more detail in Box 1.

Of the $60 \mathrm{ED}$ pharmacy team members who responded to the survey, all but one reported obtaining BPMHs as a role within their practice. However, there was considerable variation in the number of BPMHs obtained each day, perhaps because of variation in the type and extent of roles fulfilled by Canadian ED pharmacy teams, as reported in a companion article. ${ }^{47}$ Also, the number of BPMHs obtained each day was measured with a sliding-scale survey question, with a default answer of zero. It is the authors' belief that this situation resulted in 6 respondents erroneously reporting that they obtained $0 \mathrm{BPMHs}$ per day. This interpretation is based on other survey responses from the same 6 hospitals, which indicated that ED pharmacy staff collected BPMHs several times a day, using patient-specific factors for prioritization of this service. Further limitations were that survey data collected were based on subjective assessments, and the questions did not solicit data on the number of BPMHs obtained by other (nonpharmacy) ED staff.

\section{Box 1. Description of 24-h, 7-day Pharmacy Service in the Emergency Department at South Health Campus, Calgary, Alberta}

The South Health Campus is a recently opened 310-bed facility in Calgary, Alberta, with 170 presentations to the emergency department (ED) daily, of which $10.8 \%$ are admitted. This ED receives around-the-clock dedicated pharmacist coverage in the ED each day (365 days per year) — a service that is funded by the pharmacy department. The majority of this coverage is fulfilled by 3.8 full-time equivalent (FTE) pharmacists who work 8 -h shifts in the ED. The remaining ED pharmacist coverage is provided as a weekend and night shift rotation by all pharmacists at this site. This approach was taken to minimize recruitment challenges for the ED pharmacist positions without unduly compromising the level of pharmacy services in the ED. There is typically only one pharmacist available in the ED at any time, and pharmacy technicians are not yet incorporated into the ED staffing model.

The pharmacy team successfully completes $90 \%$ of best possible medication histories (BPMHs) for ED admissions, but its goal is to obtain BPMHs for all admitted ED patients. Patients are selected by convenience once they are admitted, and the receiving ward's nurses are expected to complete the BPMHs that are not completed in the ED. All hospital personnel who obtain BPMHs have received training in the form of a 15-min presentation. Although the South Health Campus uses computerized physician order entry, BPMHs are currently documented in the paper charts. For most patients admitted from the ED, this activity is performed before the ordering of home medications. ED pharmacists at the South Health Campus provide a number of other services which may prevent achievement of the $100 \%$ admission BPMH goal; some examples are laboratory culture-and-sensitivity assessments for discharged ED patients, patient education, drug information, code and trauma support, and assistance with drug distribution issues. The South Health Campus is planning to add pharmacy technicians for BPMH processes in the ED, thereby allowing pharmacists to provide more in-depth pharmaceutical care in the ED.

The initial telephone survey indicated that the EDs in at least 148 hospitals (61\% of the 243 Canadian hospitals with at least 50 acute care beds and an ED) had less than 0.5 FTE ED pharmacy services. There may have been more sites without dedicated ED pharmacy services, given that some of the 35 sites that did not respond to the detailed survey of ED pharmacy services may also have had less than 0.5 FTE ED pharmacy services. Despite previous literature suggesting that pharmacy team members are best-suited to collect BPMHs, data from this study suggest that current levels of ED pharmacy services are inadequate to support obtaining BPMHs in Canadian EDs. Many ED managers specifically identified the need for additional ED pharmacy staff to obtain BPMHs. This result is not surprising, given that obtaining BPMHs is a time-consuming activity and may best be performed by staff members who focus solely on assessing each patient's medications.

Clinical pharmacy services are known to reduce adverse drug events, improve medication adherence and appropriateness, and shorten hospital stays with no worsening of clinical outcomes. ${ }^{56,57}$ 
The cost-effectiveness of ED clinical pharmacy programs has also been demonstrated. ${ }^{58,59}$ Most importantly, clinical pharmacy services have been associated with reductions in hospital mortality rates, and obtaining BPMHs on admission has been identified as 1 of 7 key roles in this outcome. ${ }^{60}$ Having a pharmacist obtain BPMHs may facilitate the provision of other clinical pharmacy services known to improve patient outcomes, including acting as a resource to other ED staff. To increase the number of BPMHs collected, pharmacy technicians should also be involved in this activity, preferably in coordination with the pharmacist. Given that pharmacy technicians obtain BPMHs just as well as pharmacists, ${ }^{40-42}$ such a model could be a more resourceeffective approach to obtaining BPMHs in Canada. In addition, having pharmacy technicians obtain BPMHs in the ED may give pharmacists, physicians, and other members of the health care team the opportunity to provide more advanced care assessments to a greater number of ED patients.

Half of the sites that responded to this survey of ED pharmacy services had at least 0.5 FTE ED pharmacy technician; however, this study did not identify when the provision of ED pharmacy technician services began. It was not possible to estimate the presence of $\mathrm{ED}$ pharmacy technician services for the 35 hospitals that did not respond to the ED pharmacy team survey, because the presence of ED pharmacy technicians was not specifically solicited during the preliminary telephone screening.

\section{CONCLUSIONS}

Overall, these survey results suggest that the large majority of EDs in Canada do not adequately obtain BPMHs for admitted patients. Accreditation Canada has revised the medication reconciliation ROP for on-site surveys conducted in 2015 and beyond to include the expectation that medication reconciliation activities will be completed for a target group of patients without a decision to admit. To meet these requirements in Canadian EDs, significant improvements in structured processes and staffing resources are required. Many ED managers have indicated the need for expansion of pharmacy services to provide these resources. Almost half of existing Canadian ED pharmacy services were established in the 4 years preceding the survey, but the majority of Canadian hospitals do not yet have dedicated pharmacy services. ${ }^{47}$ Where such services are available, additional pharmacy staffing and improved information management processes are still required at most institutions.

\section{References}

1. Tam VC, Knowles SR, Cornish PL, Fine N, Marchesano R, Etchells EE. Frequency, type and clinical importance of medication history errors at admission to hospital: a systematic review. CMAJ. 2005;173(5):510-5.

2. Cornish PL, Knowles SR, Marchesano R, Tam V, Shadowitz S, Juurlink $\mathrm{DN}$, et al. Unintended medication discrepancies at the time of hospital admission. Arch Intern Med. 2005;165(4):424-9.

3. Vira T, Colquhoun M, Etchells EE. Reconcilable differences: correcting medication errors at hospital admission and discharge. Qual Saf Health Care. 2006;15(2):122-6.
4. Kwan Y, Fernandes OA, Nagge JJ, Wong GG, Huh JH, Hum DA, et al. Pharmacist medication assessments in a surgical preadmission clinic. Arch Intern Med. 2007;167(10):1034-40.

5. Gleason KM, McDaniel MR, Feinglass J, Baker DW, Lindquist L, Liss D, et al. Results of the Medications At Transitions and Clinical Handoffs $(\mathrm{MATCH})$ study: an analysis of medication reconciliation errors and risk factors at hospital admission. J Gen Intern Med. 2010;25(5):441-7.

6. Medication reconciliation (MedRec) [web page]. Toronto (ON): Institute for Safe Medication Practices Canada; 2011 [cited 2014 May 7]. Available from: https://www.ismp-canada.org/medrec/

7. Karnon J, Campbell F, Czoski-Murray C. Model-based cost-effectiveness analysis of interventions aimed at preventing medication error at hospital admission (medicines reconciliation). J Eval Clin Pract. 2009;15(2): 299-306.

8. Schnipper JL, Hamann C, Ndumele CD, Liang CL, Carty MG, Karson AS, et al. Effect of an electronic medication reconciliation application and process redesign on potential adverse drug events: a cluster randomized trial. Arch Intern Med. 2009;169(8):771-80.

9. Boockvar KS, Carlson LaCorte H, Giambanco V, Fridman B, Siu A. Medication reconciliation for reducing drug-discrepancy adverse events. $\mathrm{Am}$ J Geriatr Pharmacother. 2006;4(3):236-43.

10. Hohl CM, Zed PJ, Brubacher JR, Abu-Laban RB, Loewen PS, Purssell RA. Do emergency physicians attribute drug-related emergency department visits to medication-related problems? Ann Emerg Med. 2010;55(6):493-502.

11. Patel P, Zed PJ. Drug-related visits to the emergency department: how big is the problem? Pharmacotherapy. 2002;22(7):915-23.

12. Zed PJ, Abu-Laban RB, Balen RM, Loewen PS, Hohl CM, Brubacher JR, et al. Incidence, severity and preventability of medication-related visits to the emergency department: a prospective study. CMAJ. 2008;178(12):1563-9.

13. Hohl CM, Nosyk B, Kuramoto L, Zed PJ, Brubacher JR, Abu-Laban RB, et al. Outcomes of emergency department patients presenting with adverse drug events. Ann Emerg Med. 2011;58(3):270-279.e4.

14. Samoy LJ, Zed PJ, Wilbur K, Balen RM, Abu-Laban RB, Roberts M. Drugrelated hospitalizations in a tertiary care internal medicine service of a Canadian hospital: a prospective study. Pharmacotherapy. 2006:26(11): 1578-86.

15. Zed PJ. Drug-related visits to the emergency department. J Pharm Pract. 2005; 18:329-35.

16. Baena MI, Faus MJ, Fajardo PC, Luque FM, Sierra F, Martinez-Olmos J, et al. Medicine-related problems resulting in emergency department visits. Eur J Clin Pharmacol. 2006;62(5):387-93.

17. Emergency department. In: Qmentum program standards. Version 4. Ottawa (ON): Accreditation Canada; 2011.

18. Medication reconciliation. Edmonton (AB): Canadian Safer Healthcare Now; 2012 [cited 2013 Dec 20]. Available from: www.saferhealthcarenow.cal EN/Interventions/medrec/Pages/default.aspx

19. Canadian hospital pharmacy 2015 (CSHP 2015). Ottawa (ON): Canadian Society of Hospital Pharmacists; 2008 [cited 2014 Feb 25]. Available from: www.cshp.ca/dms/dmsView/2_CSHP-2015-Goals-and-Objectives-Feb25\%2707-w-Appdx-rev-May\%2708.pdf

20. Emergency department. In: Qmentum program standards. Version 9. Ottawa $(\mathrm{ON})$ : Accreditation Canada; 2014.

21. Shepherd G, Schwartz RB. Frequency of incomplete medication histories obtained at triage. Am J Health Syst Pharm. 2009;66(1):65-9.

22. Mazer M, DeRoos F, Hollander JE, McCusker C, Peacock N, Perrone J. Medication history taking in emergency department triage is inaccurate and incomplete. Acad Emerg Med. 2011;18(1):102-4.

23. Thompson CA. JCAHO views medication reconciliation as adverse-event prevention. Am J Health Syst Pharm. 2005;62(15):1528,1530,1532.

24. Santell JP. Reconciliation failures lead to medication errors. Jt Comm J Qual Patient Saf. 2006;32(4):225-9.

25. Carter MK, Allin DM, Scott LA, Grauer D. Pharmacist-acquired medication histories in a university hospital emergency department. Am J Health Syst Pharm. 2006;63(24):2500-3

26. Vasileff HM, Whitten LE, Pink JA, Goldsworthy SJ, Angley MT. The effect on medication errors of pharmacists charting medication in an emergency department. Pharm World Sci. 2009;31(3):373-9.

27. De Winter S, Spriet I, Indevuyst C, Vanbrabant P, Desruelles D, Sabbe M, et al. Pharmacist- versus physician-acquired medication history: a prospective study at the emergency department. Qual Saf Health Care. 2010;19(5):371-5.

28. Nickerson A, MacKinnon NJ, Roberts N, Saulnier L. Drug-therapy problems, inconsistencies and omissions identified during a medication reconciliation and seamless care service. Healthc Q. 2005;8 Spec No.:65-72. 
29. Cornu P, Steurbaut S, Leysen T, De Baere E, Ligneel C, Mets T, et al. Effect of medication reconciliation at hospital admission on medication discrepancies during hospitalization and at discharge for geriatric patients. Ann Pharmacother. 2012;46(4):484-94.

30. Hayes BD, Donovan JL, Smith BS, Hartman CA. Pharmacist-conducted medication reconciliation in an emergency department. Am J Health Syst Pharm. 2007;64(16):1720-3.

31. Kent AJ, Harrington L, Skinner J. Medication reconciliation by a pharmacist in the emergency department: a pilot project. Can J Hosp Pharm. 2009; 62(3):238-42.

32. Ong SW, Fernandes OA, Cesta A, Bajcar JM. Drug-related problems on hospital admission: relationship to medication information transfer. Ann Pharmacother. 2006;40(3):408-13.

33. Mueller SK, Sponsler KC, Kripalani S, Schnipper JL. Hospital-based medication reconciliation practices: a systematic review. Arch Intern Med. 2012;172(14):1057-69.

34. Pal A, Babbott S, Wilkinson ST. Can the targeted use of a discharge pharmacist significantly decrease 30-day readmissions? Hosp Pharm. 2013; 48(5):380-8.

35. Medication reconciliation: statement on the role of the pharmacist (2009). Ottawa (ON): Canadian Society of Hospital Pharmacists; 2009 [cited 2014 Feb 27]. Available from: www.cshp.ca/dms/dmsView/1_S_Med_Rec_ 2009.pdf

36. ASHP Council on Pharmacy Practice. ASHP statement on the pharmacist's role in medication reconciliation. Am J Health Syst Pharm. 2013;70(5):453-6.

37. Fernandes OA. Medication reconciliation: practical tips, strategies and tools for pharmacists. Pharm Pract. 2009;:24-32,52-5. Available from: https:// bcpsqc.ca/documents/2012/09/Fernandes-Medication-ReconciliationPractical-Tips-Strategies-and-Tools-for-Pharmacists.pdf

38. Thomas M, Cross S, Nagra M, Bullock A. Empowering technicians to work in extended clinical roles. Pharm J. 2008;15:145-6. Available from: www.pharmaceutical-journal.com/news-and-analysis/news/empoweringtechnicians-to-work-in-extended-clinical-roles/10006669.article

39. Knight H, Edgerton L, Foster R. Pharmacy technicians obtaining medication histories within the emergency department. Am J Health Syst Pharm. 2010;67(7):512-4.

40. Smith SB, Mango MD. Pharmacy-based medication reconciliation program utilizing pharmacists and technicians: a process improvement initiative. Hosp Pharm. 2013;48(2):112-9.

41. Leung M, Jung J, Lau W, Kiaii M, Jung B. Best possible medication history for hemodialysis patients obtained by a pharmacy technician. Can J Hosp Pharm. 2009;62(5):386-91.

42. Johnston R, Saulnier L, Gould O. Best possible medication history in the emergency department: comparing pharmacy technicians and pharmacists. Can J Hosp Pharm. 2010;63(5):359-65.

43. Eppert HD, Reznek AJ; American Society of Health-System Pharmacists. ASHP guidelines on emergency medicine pharmacist services. Am J Health Syst Pharm. 2011;68(23):e81-95.

44. Optimizing medication safety at care transitions - creating a national challenge [proceedings]. Toronto $(\mathrm{ON})$ : Institute for Safe Medication Practices Canada, Canada Health Infoway, Safer Healthcare Now, Canadian Patient Safety Institute; 2011 [cited 2014 Feb 17]. Available from: https:// www.ismp-canada.org/download/MedRec/MedRec_National_ summitreport_Feb_2011_EN.pdf

45. Babich M, Bornstein C, Bussières JF, Doucette D, Hall KW, Lefebvre P, et al., editors. Hospital pharmacy in Canada 2011/2012 report. Eli Lilly Canada Inc; 2013 [cited 2014 Feb 17]. Available from: www.lilly hospitalsurvey.ca/hpc2/content/2012_report/FULL-2012.pdf

46. Pedersen CA, Schneider PJ, Scheckelhoff DJ. ASHP national survey of pharmacy practice in hospital settings: dispensing and administration-2008. Am J Health Syst Pharm. 2009;66(10):926-46.

47. Wanbon R, Lyder C, Villeneuve E, Shalansky S, Manuel L, Harding M. Clinical pharmacy services in Canadian emergency departments: a national survey. Can J Hosp Pharm. 2015;68(3):191-201.

48. Draugalis JR, Coons SJ, Plaza CM. Best practices for survey research reports: a synopsis for authors and reviewers. Am J Pharm Educ. 2008; 72(1):Article 11.

49. Ding R, Zeger SL, Steinwachs DM, Ortmann MJ, McCarthy ML. The validity of self-reported primary adherence among Medicaid patients discharged from the emergency department with a prescription medication. Ann Emerg Med. 2013;62(3):225-34.

50. Price M, Bowen M, Lau F, Kitson N, Bardal S. Assessing accuracy of an electronic provincial medication repository. BMC Med Inform Decis Mak. 2012;12:42.
51. Kalb K, Shalansky S, Legal M, Khan N, Ma I, Hunte G. Unintended medication discrepancies associated with reliance on prescription databases for medication reconciliation on admission to a general medical ward. Can J Hosp Pharm. 2009;62(4):284-9.

52. Lo A, Shalansky SJ, Menezes J. Comparison of the completeness of prescription medication histories for hospitalized geriatric patients documented by different health care professionals. Can J Hosp Pharm. 2004;57(1):32-8.

53. Accreditation Canada, Canadian Institute for Health Information, Canadian Patient Safety Institute, Institute for Safe Medication Practices Canada. Medication reconciliation in Canada: raising the bar-progress to date and the course ahead. Ottawa (ON): Accreditation Canada; 2012.

54. Thomasset KB, Faris R. Survey of pharmacy services provision in the emergency department. Am J Health Syst Pharm. 2003;60(15):1561-4.

55. Pedersen CA, Schneider PJ, Scheckelhoff DJ. ASHP national survey of pharmacy practice in hospital settings: monitoring and patient education2012. Am J Health Syst Pharm. 2013;70(9):787-803.

56. Rothschild JM, Churchill W, Erickson A, Munz K, Schuur JD, Salzberg $\mathrm{CA}$, et al. Medication errors recovered by emergency department pharmacists. Ann Emerg Med. 2010;55(6):513-21.

57. Kaboli PJ, Hoth AB, McClimon BJ, Schnipper JL. Clinical pharmacists and inpatient medical care: a systematic review. Arch Intern Med. 2006; 166(9):955-64.

58. Levy DB. Documentation of clinical and cost-saving pharmacy interventions in the emergency room. Hosp Pharm. 1993;28(7):624-7,630-4,653.

59. Lada P, Delgado G Jr. Documentation of pharmacists' interventions in an emergency department and associated cost avoidance. Am J Health Syst Pharm. 2007;64(1):63-8.

60. Bond CA, Raehl CL. Clinical pharmacy services, pharmacy staffing, and hospital mortality rates. Pharmacotherapy 2007;27(4):481-93.

Richard Wanbon, BSc, BSc(Pharm), ACPR, PharmD, is a Clinical Pharmacy Specialist (Emergency Medicine), Pharmacy Department, Royal Jubilee Hospital, Island Health Authority, Victoria, British Columbia.

Catherine Lyder, BSC(Pharm), MHSA, is Coordinator of Professional and Membership Affairs, Canadian Society of Hospital Pharmacists, Ottawa, Ontario.

Eric Villeneuve, BPharm, MSc, PharmD, is a Clinical Pharmacist (Emergency Medicine), Pharmacy Department, McGill University Health Centre, Montreal, Quebec.

Stephen Shalansky, BSC(Pharm), ACPR, PharmD, FCSHP, is Clinical Coordinator, Pharmacy Department, Providence Healthcare, Lower Mainland Pharmacy Services, Vancouver, British Columbia. He is also a Clinical Professor with the Faculty of Pharmaceutical Sciences, The University of British Columbia, Vancouver, British Columbia.

Leslie Manuel, BSC, BSC(Pharm), ACPR, PharmD, is Pharmacy Clinical Manager and Clinical Pharmacist (Emergency Medicine), Pharmacy Department, The Moncton Hospital, Horizon Health Network, Moncton, New Brunswick.

Melanie Harding, BSP, ACPR, is a Clinical Pharmacist with the Emergency and Home Parenteral Therapy Program, Pharmacy Department, South Health Campus, Alberta Health Services, Calgary, Alberta.

Competing interests: None declared.

\section{Address correspondence to:}

Dr Richard Wanbon

Royal Jubilee Hospital - Pharmacy Administration

1952 Bay Street

Victoria BC V8R 1J8

e-mail: Richard.Wanbon@viha.ca

Acknowledgements: The authors would like to thank Patrick Falkiner, Camille Petit, James Nataraj, and Erin Dunn for their assistance with identifying survey recipients; Heather Goodland for her contributions to the survey assessment; and Paul Murgoi for his verification of the French translation of study materials. This research group was formed within the Canadian Society of Hospital Pharmacists' Emergency Medicine Pharmacy Specialty Network.

Funding: None received. 